\title{
Meta-analysis of the prevalence of tuberculosis in diabetic patients and its association with cigarette smoking in African and Asian countries
}

\author{
Fasil Wagnew $^{1 *}$, Setegn Eshetie ${ }^{2}$, Animut Alebel ${ }^{1}$, Getenet Dessie ${ }^{1}$, Cheru Tesema ${ }^{1}$ \\ and Amanuel Alemu Abajobir ${ }^{3}$
}

\begin{abstract}
Objective: This systematic review and meta-analysis was undertaken to estimate the prevalence of tuberculosis in diabetic patients and to determine the effect of cigarette smoking.

Results: A total of 15 studies was included in the meta-analysis. The pooled overall prevalence of tuberculosis in diabetes was $4.72 \%$ (95\% Cl 3.62-5.83\%). In sub-group analyses, the prevalence was 5.13\% (95\% Cl 4.34-5.92\%) in Africa, followed by $4.16 \%$ (95\% Cl 2.9-5.4\%) in Asia. The odd ratio of tuberculosis among diabetes patients was 7.6 (95\% Cl 1.46-39) in cigarette smokers as compared to nonsmokers. Publication bias was detected based on graphic asymmetry of fun-nel plots, Begg's and Egger's tests $(p<0.05)$. Tuberculosis is a common co-morbidity in diabetic patients. Tuberculosis-diabetes co-morbidity is significantly higher in cigarette smokers.
\end{abstract}

Keywords: Tuberculosis, Diabetes mellitus, Cigarette smoking, Systematic review and meta-analysis

\section{Introduction}

Tuberculosis (TB) is an infectious disease caused by various strains of mycobacterium, particularly Mycobacterium tuberculosis, and usually affects the respiratory system [1]. Diabetes mellitus (DM) is a complex metabolic disorder featured by a high level of blood sugar either because of inadequate insulin production or less sensitivity of cells responsible to the insulin metabolism [2], and associated with impairment of cell-mediated immunity involving the lungs, kidney dysfunctions, and micronutrient deficiencies [3]. The World Health Organization (WHO, 2017) reported that there were 10.4 million TB new cases and 1.7 million deaths due to TB [4]. Similarly, 415 million cases and 5.0 million deaths due to DM were registered [5]. Tragically, $95 \%$ TB and 75\%

${ }^{*}$ Correspondence: fasilw.n@gmail.com

${ }^{1}$ College of Health Science, Debre Markos University, Debre Markos, Ethiopia

Full list of author information is available at the end of the article
DM cases exist in low and middle income countries (e.g., Africa and Southeast Asia) [9].

$\mathrm{TB}$ and DM co-morbidity is considerably an emerging public health problem [6], and TB is the third leading cause of death among patients with non-communicable disease (NCD), particularly DM [7]. For example, the number of patients with TB-DM co-morbidity is higher than the number of patients with TB-HIV(Human Immuno Deficiency) co-infection globally [8]. That is, the rising prevalence of DM is becoming a challenge to TB control $[9,10]$ and vice versa. This may partially be due to the risk of uncontrolled hyperglycemia for $\mathrm{TB}$ [11] and diabetic [12] patients with substantial immuno compromisation [3]. That said, people with diabetes are three times more likely to develop $\mathrm{TB}$ when exposed and approximately $15 \%$ of TB globally is thought to be related to diabetes [13]. Moreover, those people with $\mathrm{TB}$ and coexisting diabetes have 4 times higher risk of worsening $\mathrm{TB}$ treatment outcomes and death during the course of TB regimen [14]. In addition, this may be 
more complicated by common risk factors for TB including HIV, malnutrition, alcoholism and cigarette smoking [12].

A previous study of TB-DM co-morbidity has reported high prevalence of TB in DM patients, ranging from 1.7 to $36 \%$ [9]. As a result, WHO has strongly recommended a collaborative framework for clinical management and control of TB-DM co-morbidity. That is, people with diabetes to be screened for cough of 2 weeks or more at the time of diagnosis for diabetes and, possibly, during regular follow-ups. Thus, three important intervention strategies, namely, establishing mechanisms of collaboration between TB and DM control programs, early detection and management of TB in patients with $\mathrm{DM}$, and early detection and management of DM in TB patients have been recommended [15]. These strategies may also have pivotal roles, notably for high TB burden countries to mitigate the dual burden of TB-DM co-morbidity. Thus, it is crucial to understand the prevalence of TB-DM co-morbidity particularly in low and middle-income countries.

Furthermore, cigarette smoking has adverse effects on respiratory function and is associated with an increased risk of respiratory tract infection and TB-DM co-morbidity [16-19]. Cognizant to this, WHO and International Union Against Tuberculosis and Lung Disease (The Union) have encouraged a National TB Programme to address the combined challenges of smoking, diabetes and TB $[20,21]$.

Generally, previous TB-DM co-morbidity studies, mainly from African countries, on bi-directional screenings of $\mathrm{TB}$ and $\mathrm{DM}$ and have not considered the risk of cigarette smoking. In another words, even though some previous studies [22, 23] determined the association between smoking status and the risk of TB in DM patients, the evidence base still remains inconsistence and inconclusive. This systematic review and meta-analysis is therefore aimed to summarize the prevalence of $\mathrm{TB}$ in DM adult patients and its association with history of cigarette smoking.

\section{Main text Methods}

\section{Study design and search strategy}

This systematic review and meta-analysis was carried out using both published and unpublished literature to estimate the prevalence of $\mathrm{TB}$ among diabetes patients and to determine the risk of TB-DM co-morbidity in cigarette smoking patients. Studies were found through electronic and manual searches using databases, Psych INFO, EMBASE, MEDLINE/PubMed, Google scholar and Google for gray literature from 1980-2017. The search terms were used, entering the following key terms: "prevalence" OR "Epidemiology" AND "tuberculosis," OR "TB" AND "Diabetes Mellitus," OR "DM" OR "Diabet" "Co-morbid" AND Asian countries" OR "African countries". Electronic searches were supplemented by screening the reference lists of included studies, expert recommendations and hand searches for sources of gray literature. The preferred reporting of systematic reviews and meta-analysis (PRISMA) guidelines were used [24] for the review.

\section{Inclusion criteria}

Included studies were those that obtained ethical approval and were undertaken in high TB burden countries (African and Asian countries) and/or reported the prevalence of $\mathrm{TB}$ among diabetes patients and/or determine the effect of cigarette smoking in these patients. Peer-reviewed studies with cross-sectional survey or case-series designs, and those studies that involved primary outcome(s) of interest were included.

\section{Exclusion criteria}

Those studies that reported incidence, only multi-drug resistance $\mathrm{TB}$ and latent $\mathrm{TB}$ were excluded from the analysis.

\section{Data extraction}

Two reviewers (FW and SE) screened the titles and abstracts of identified studies and assessed the full text of potentially eligible studies. Any controversy was resolved by consensus. We made some efforts to communicate the authors whenever further information was needed. Data from the included studies were extracted independently by these reviewers. Interestingly, we checked a random sample of $30 \%$ of the extracted data and found no difference. Data on author(s), study year, region of study, study design and sample size were extracted using Microsoft excel. The overall prevalence of TB in diabetic patients was also extracted from each included study. Moreover, data on the risk of cigarette smoking among these patients were extracted. AAA critically reviewed the manuscript.

\section{Quality appraisal}

Articles were assessed for quality score using NewcastleOttawa Scale adapted for cross-sectional studies quality assessment tool, with a score of $\geq 5$ out of 10 considered as high quality score. Two authors (FW, SE) assessed the quality of each paper. The reviewers compared quality appraisal scores and resolved any disagreements before calculating the final appraisal score. All included studies were of high quality score. 


\section{Data analysis}

Meta-analysis of pooled prevalence of TB in DM patients was carried out using a random-effects model, generating a pooled prevalence with $95 \%$ CIs, using STATA/se version 14. Subgroup analyses by continents (Africa and Asia) were carried out because of significant heterogeneity between studies and/or countries.

OR of TB among diabetic patients with cigarette smokers (compared to nonsmokers) was also determined. Heterogeneity among studies was estimated using the $\mathrm{I}^{2}$ statistics [25]. Publication bias was determined based on the symmetry of fun-nel plots [26], Begg's and Egger's tests [27]. As well, the trim-and-fill analysis was considered to estimate the final effect-size while publication bias detected [28].

\section{Results}

After screening for titles, 1313 studies were excluded because of unrelated topics and duplication. The fulltexts of 31 studies were screened and 16 studies of which were subsequently omitted from the meta-analysis for there were insufficient data on outcome(s) of interest. A total of 15 studies representing 23,068 participants, which fulfilled the eligibility criteria, were included in the final meta-analysis (Additional file 1: Figure S1). Sixteen studies were excluded because of 2 studies were reported TB incidence done in Korea and Indonesia [29, 30], 11 studies were not reported outcome of interest [31-41], 1 MDR-TB [42], 2 studies were explore pharmacological aspect of TB-DM $[43,44])$.

\section{Prevalence of TB among DM patients}

Among the 15 cross-sectional studies included, 9 (52.6\%) were from the Asian countries and the prevalence ranged from $0.38 \%$ in Taiwan [45] to $14 \%$ in Pakistan [46]. Six (36.8\%) prevalence studies were conducted in African countries, and the prevalence revealed as low as $3.4 \%$ in South Africa [47] and as high as $6.2 \%$ in Ethiopia [22] (Tables 1).

\section{Prevalence of TB among DM patients}

The overall pooled prevalence of TB among DM patients was $4.72 \%$ (95\% CI 3.62-5.83). Based on subgroup analyses by continents, the pooled prevalence of TB among DM patients was 4.16\% (95\% CI 2.9-5.42) in Asia and 5.13\% (95\% CI 4.34-5.92) in Africa (Fig. 1).

\section{Effect of cigarette smoking on TB-DM co-morbidity}

To determine the association of cigarette smoking with TB-DM co-morbidity, we included 3 studies which reported data on the prevalence of $\mathrm{TB}$ among $\mathrm{DM}$ patients who had a history of cigarette smoking. It was shown that the risk of TB-DM co-morbidity was more than 7 (95\% CI 1.46-39.53) times higher in patients who had a history of cigarette smoking as compared to their nonsmoker counterparts (Fig. 2).

\section{Publication bias}

Publication bias was detected based on graphic asymmetry of funnel plots, and Egger's test $(\mathrm{p}<0.05)$. However, Begg's test indicated no publication bias (Additional file 2: Fig S2). Considering the conflicting evidence on the

Table 1 The descriptive summary of 15 studies on the prevalence of TB among DM patients and its associated with history of smoking in Africa and Asia with high TB burden

\begin{tabular}{|c|c|c|c|c|c|}
\hline Author, year, country & $\begin{array}{l}\text { Study region } \\
\text { and country }\end{array}$ & DM & $\mathrm{TB}$ & Prevalence (\%) & Quality score \\
\hline Tripathy et al. 1984, India [58] & Asia & 219 & 9 & 4.1 & 6 \\
\hline Swai et al. 1990, Tanzania [59] & Africa & 1250 & 70 & 5.6 & 7 \\
\hline Feleke et al. 1999, Ethiopia [60] & Africa & 1352 & 78 & 5.77 & 6 \\
\hline Qayyum et al. 2004, Pakistan [61] & Asia & 95 & 9 & 9.47 & 7 \\
\hline Jabbar et al. 2006, Pakistan [62] & Asia & 1458 & 173 & 11.8 & 7 \\
\hline Webb et al. 2009, S.Africa [47] & Africa & 258 & 9 & 3.48 & 7 \\
\hline Amin et al. 2011, Pakistan [46] & Asia & 100 & 14 & 14 & 8 \\
\hline Kirui et al. 2012, Kenya [63] & Africa & 1376 & 77 & 5.6 & 7 \\
\hline Jali et al. 2013, India [64] & Asia & 4118 & 111 & 2.69 & 6 \\
\hline Kumpatla et al. 2013, India [65] & Asia & 7083 & 50 & 0.7 & 6 \\
\hline Prakash et al. 2013, India [66] & Asia & 1670 & 47 & 2.8 & 7 \\
\hline Amare et al. 2013, Ethiopia [22] & Africa & 225 & 14 & 6.2 & 8 \\
\hline Lin et al. 2015, Taiwan [45] & Asia & 3087 & 12 & 0.38 & 9 \\
\hline Rao et al. 2015, India [67] & Asia & 96 & 10 & 10.4 & 6 \\
\hline Tiroro et al. 2015, Ethiopia [23] & Africa & 681 & 26 & 3.8 & 8 \\
\hline
\end{tabular}




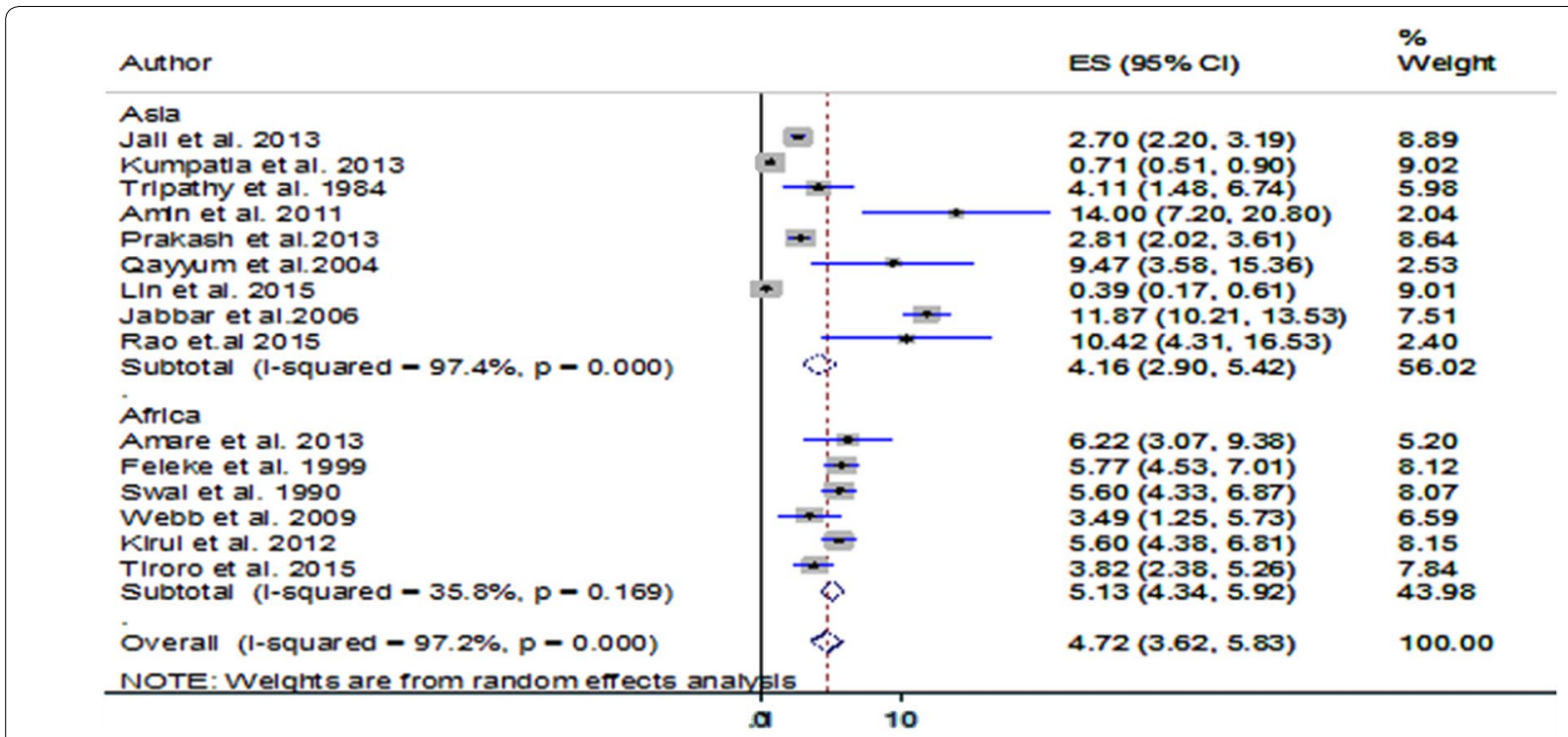

Fig. 1 Pooled prevalence of TB among DM patients in African and Asian countries with high TB-burden

\begin{tabular}{|c|c|c|}
\hline Study & & $\%$ \\
\hline ID & ES $(95 \% \mathrm{Cl})$ & Welght \\
\hline Lin et al. 2015 & $2.08(0.55,7.86)$ & 33.48 \\
\hline Tiroro et al. 2015 & $26.20(10.13,67.75)$ & 37.48 \\
\hline A mare et al. 2013 & $6.87(1.21,38.96)$ & 29.04 \\
\hline Overall (l-squared $=78.9 \%, p=0.009$ ) & $7.60(1.46,39.53)$ & 100.00 \\
\hline NOTE: Welghts are from random effects analysis & & \\
\hline
\end{tabular}

possible publication bias, trim-and-fill method was used to estimate the publication bias [28]. Though this method indicated 2 potential studies missing, the final results were almost similar to the original findings after 2 virtual studies were appended, indicating that the results of this meta-analysis were steady.

\section{Discussion}

The present meta-analysis was conducted to determine the point prevalence of $\mathrm{TB}$ among diabetic patients and its association with cigarette smoking in Asian and African countries with a high TB burden. Existing evidence based on data from 15 included studies with 23,068 study participants revealed a $4.7 \%$ point prevalence of TB among diabetic patients in these countries. Poor DM control (as indicated by high HbA1c level) may be associated with differences in the physiological/pathological functions that perhaps boost progression to active TB disease [48] in these patients. This finding is higher as compared to a previous systematic review by Jeon. et al. [9]. The observed variations might be due to aging, changes in lifestyle, and socioeconomic factors. This may be that some countries are experiencing the fastest increase in DM prevalence along with the highest burden of TB and HIV $[49,50]$. Despite substantial overlaps of CIs, subgroup analyses by continents suggested the point prevalence of TB among diabetic patients was fairly higher in Africa as compared to Asia. This finding is supported by previous systematic review that reported higher median prevalence of TB in African diabetic patients than the Asian counterparts [51]. 
This discrepancy might partly be attributable to the functional "Collaborative Framework for the care and control of Diabetes and Tuberculosis" to detect and treat TB in diabetic patients [3] that might have contributed to the lower prevalence of TB-DM co-morbidity. In other words, African countries (e.g., sub-Saharan Africa) have recently been experiencing DM and other chronic conditions [52] possibly because of lack of such an intervention.

A further aim of this study was to determine the effect of cigarette smoking on the occurance of TB among DM patients. Cigarette smoking was found to be significantly associated with TB-DM co-morbidity. This was in accordance with another systematic review that reported exposure to environmental tobacco smoke increases the risks of developing TB disease and infection [53]. Another systematic review by Lonnroth, et al. [54] also revealed that under-nutrition, cigarette smoking and inappropriate alcohol consumption can double or triple the risk of TB-DM co-morbidity. This could be because of the complex etiopathological mechanisms in cigarette smokers resulting in inflammation and oxidative stress that may increase the risk of developing TB-DM [55]. Furthermore, cigarette smoking can increase the availability of iron in lower respiratory tract part [56] that may react with nitric oxide to produce toxic chemicals that can decrease immunity [57].

\section{Conclusion}

TB is a common co-morbidity in diabetic patients. TB-DM co-morbidity is significantly higher in cigarette smokers. Screening for TB in diabetic patients as well as lifestyle intervention may improve early case detection, prevent transmission and decrease the risk of TB-DM co-morbidity.

\section{Limitations}

The inclusion of studies published only in English may compromise representativeness (language bias). Incapability to reliable differentiate between type-I and type-II diabetes mellitus. As well, because of lack of uniformity across each study, we did not explore other factors affecting TB-DM co-morbidity but cigarette smoking.

\section{Additional files}

Additional file 1: Figure S1. Flow chart describing selection of studies for a systematic review and meta-analysis of the prevalence of tuberculosis among diabetes patients and its association with cigarette smoking.

Additional file 2: Figure S2. Funnel plots, exploring publication bias for the analysis of pooled estimate.

\section{Abbreviations}

DM: diabetes mellitus; TB: tuberculosis; WHO: World Health Organization.

\section{Authors' contributions}

FW involved in the conception of the research idea; (FW, SE) undertook data extraction, analysis, interpretation, and manuscript write-up. (FW, SE and AAA) interpreted the results, and drafted the manuscript. (AA, GD, CT) revised the manuscript. All authors read and approved the final manuscript.

\section{Author details}

${ }^{1}$ College of Health Science, Debre Markos University, Debre Markos, Ethiopia. ${ }^{2}$ College of Health Science, University of Gondar, Gondar, Ethiopia. ${ }^{3}$ Faculty of Medicine, The University of Queensland, Brisbane, Australia.

\section{Acknowledgements}

The authors would like to acknowledge the Debre Markos University library for providing us with a wide range of available online databases.

\section{Competing interests}

The authors declare that they have no competing interests.

\section{Availability of data and materials}

The datasets used and/or analysed during the current study are available from the corresponding author on reasonable request.

Consent to publication

Not applicable.

Ethics approval and consent to participate

Not applicable.

Funding

Not applicable.

\section{Publisher's Note}

Springer Nature remains neutral with regard to jurisdictional claims in published maps and institutional affiliations.

Received: 24 March 2018 Accepted: 3 May 2018

Published online: 15 May 2018

\section{References}

1. Smith I. Mycobacterium tuberculosis pathogenesis and molecular determinants of virulence. Clin Microbiol Rev. 2003;16(3):463-96.

2. International Diabetes Federation. Diabetes blue circle symbol. Brussels: International Diabetes Federation; 2006.

3. Lin Y, Li L, Mi F, Du J, Dong Y, Li Z, Qi W, Zhao X, Cui Y, Hou F. Screening patients with diabetes mellitus for tuberculosis in China. Tropical Med Int Health. 2012;17(10):1302-8.

4. World Health Organization. Global tuberculosis report. Geneva: World Health Organization; 2017.

5. International Diabetes Federation. Diabetes atlas. 7th ed. Brussels: International Diabetes Federation; 2015.

6. Syal K, Srinivasan A, Banerjee D. VDR, RXR, coronin-1 and interferony levels in PBMCs of type-2 diabetes patients: molecular link between diabetes and tuberculosis. Indian J Clin Biochem. 2015;30(3):323-8.

7. Banerjee D, Bhattacharyya R, Kaul D, Sharma P. Diabetes and tuberculosis: analysis of a paradox. Adv Clin Chem. 2011:53:139.

8. Ruslami R, Aarnoutse RE, Alisjahbana B, Van Der Ven AJ, Van Crevel R. Implications of the global increase of diabetes for tuberculosis control and patient care. Trop Med Int Health. 2010;15(11):1289-99.

9. Jeon CY, Harries AD, Baker MA, Hart JE, Kapur A, Lönnroth K, Ottmani SE, Goonesekera S, Murray MB. Bi-directional screening for tuberculosis and diabetes: a systematic review. Trop Med Int Health. 2010;15(11):1300-14.

10. Riza AL, Pearson F, Ugarte-Gil C, Alisjahbana B, van de Vijver S, Panduru NM, Hill PC, Ruslami R, Moore D, Aarnoutse R. Clinical management of concurrent diabetes and tuberculosis and the implications for patient services. Lancet Diabetes Endocrinol. 2014;2(9):740-53.

11. USAID Health-Related Research and Development Progress Report, Report to Congress; 2013. p. 25-27. Available at: https://www.usaid.gov/ sites/default/files/documents/1864/Health\%20Research\%20Report.pdf 
12. Baker MA, Harries AD, Jeon CY, Hart JE, Kapur A, Lönnroth K, Ottmani S-E, Goonesekera SD, Murray MB. The impact of diabetes on tuberculosis treatment outcomes: a systematic review. BMC Med. 2011;9(1):81.

13. International Diabetes Federation (IDF). Global Diabetes Plan 2011-2021. Brussels: International Diabetes Federation. Available at: https://www. worlddiabetesfoundation.org/sites/default/files/TB-diabetes\%20co-epide mic\%20fact\%20sheet_March2014\%20update.pdf

14. The International Union against Tuberculosis and Lung Disease and the World Diabetes Foundation. The growing threat of the double burden of diabetes and tuberculosis. 2014. Available at: https://www.worlddiabe tesfoundation.org/sites/default/files/TB-diabetes\%20co-epidemic\%20fac t\%20sheet_March2014\%20update.pdf

15. World Health Organization. Collaborative framework for care and control of tuberculosis and diabetes. Geneva: World Health Organization; 2013.

16. Feng $J-Y$, Huang S-F, Ting W-Y, Lee M-C, Chen Y-C, Lin Y-Y, Lee Y-C, Su W-J. Impact of cigarette smoking on latent tuberculosis infection: does age matter? Eur Respir J. 2014;43(2):630-2.

17. Garmendia J, Morey P, Bengoechea J. Impact of cigarette smoke exposure on host-bacterial pathogen interactions. Eur Respir J. 2012;39(2):467-77.

18. Leung CC, Yew WW, Law WS, Tam CM, Leung M, Chung YW, Cheung KW, Chan KW, Fu F. Smoking and tuberculosis among silicotic patients. Eur Respir J. 2007:29(4):745-50.

19. Shang S, Ordway D, Henao-Tamayo M, Bai X, Oberley-Deegan R, Shanley C, Orme IM, Case S, Minor M, Ackart D. Cigarette smoke increases susceptibility to tuberculosis-evidence from in vivo and in vitro models. J Infect Dis. 2011;203(9):1240-8

20. Bissell $K$, Fraser T, Chiang CY, Enarson DA. Smoking cessation and smoke free environments for tuberculosis patients, vol. 20. 2nd ed. Paris: International Union Against Tuberculosis and Lung Disease; 2010. p. 2-50.

21. World Health Organization, International Union Against Tuberculosis and Lung Disease. Collaborative framework for care and control of tuberculosis and diabetes. World Health Organ Doc. 2011;15:1-40.

22. Amare H, Gelaw A, Anagaw B, Gelaw B. Smear positive pulmonary tuberculosis among diabetic patients at the Dessie referral hospital, Northeast Ethiopia. Infect Dis Poverty. 2013;2(1):6.

23. Sisay T. The magnitude and associated factors of tuberculosis among diabetic patients at Tikur Anbessa specialized teaching hospital in Addis Ababa, Ethiopia. MPH thesis, Addis Ababa University. 2015. Available at: https://oatd.org/oatd/search?q=sisay+tiroro\%26form=basic.

24. Liberati A, Altman DG, Tetzlaff J, Mulrow C, Gotzsche PC, loannidis JP, Clarke M, Devereaux PJ, Kleijnen J, Moher D. The PRISMA statement for reporting systematic reviews and meta-analyses of studies that evaluate health care interventions: explanation and elaboration. J Clin Epidemiol. 2009;62(10):e1-34.

25. Higgins JP, Thompson SG, Deeks JJ, Altman DG. Measuring inconsistency in meta-analyses. BMJ. 2003;327(7414):557-60

26. Borenstein M, Hedges LV, Higgins J, Rothstein HR. A basic introduction to fixed-effect and random-effects models for meta-analysis. Res Synth Methods. 2010;1 (2):97-111.

27. Begg CB, Mazumdar M. Operating characteristics of a rank correlation test for publication bias. Biometrics. 1994;1:1088-101.

28. Duval S, Tweedie R. Trim and fill: a simple funnel-plot-based method of testing and adjusting for publication bias in meta-analysis. Biometrics. 2000;56(2):455-63.

29. Kim S, Hong Y, Lew W, Yang S, Lee E. Incidence of pulmonary tuberculosis among diabetics. Tuber Lung Dis. 1995;76(6):529-33.

30. Alisjahbana B, Van Crevel R, Sahiratmadja E, Den Heijer M, Maya A, Istriana E, Danusantoso H, Ottenhoff T, Nelwan R, Van Der Meer J. Diabetes mellitus is strongly associated with tuberculosis in Indonesia. Int J Tuberc Lung Dis. 2006:10(6):696-700

31. Dooley KE, Tang T, Golub JE, Dorman SE, Cronin W. Impact of diabetes mellitus on treatment outcomes of patients with active tuberculosis. Am J Trop Med Hyg. 2009;80(4):634-9.

32. Goldhaber-Fiebert JD, Jeon CY, Cohen T, Murray MB. Diabetes mellitus and tuberculosis in countries with high tuberculosis burdens: individual risks and social determinants. Int J Epidemiol. 2011:40(2):417-28.

33. Harries A, Lin Y, Satyanarayana S, Lönnroth K, Li L, Wilson N, Chauhan L, Zachariah R, Baker M, Jeon C. The looming epidemic of diabetes-associated tuberculosis: learning lessons from HIV-associated tuberculosis. Int J Tuberc Lung Dis. 2011;15(11):1436-45.
34. Kumar A, Gupta D, Nagaraja SB, Nair SA, Satyanarayana S, Zachariah R, Harries A. Screening of patients with diabetes mellitus for tuberculosis in India. Trop Med Int Health. 2013;18(5):638-45.

35. Pizzol D, Di Gennaro F, Chhaganlal KD, Fabrizio C, Monno L, Putoto G, Saracino A. Tuberculosis and diabetes: current state and future perspectives. Trop Med Int Health. 2016;21 (6):694-702.

36. Singla R, Khan N, Al-Sharif N, Al-Sayegh M, Shaikh M, Osman M. Influence of diabetes on manifestations and treatment outcome of pulmonary TB patients. Int J Tuberc Lung Dis. 2006;10(1):74-9.

37. Viswanathan V, Kumpatla S, Aravindalochanan V, Rajan R, Chinnasamy C, Srinivasan R, Selvam JM, Kapur A. Prevalence of diabetes and pre-diabetes and associated risk factors among tuberculosis patients in India. PLoS ONE. 2012;7(7):e41367.

38. Zheng C, Hu M, Gao F. Diabetes and pulmonary tuberculosis: a global overview with special focus on the situation in Asian countries with high TB-DM burden. Global Health Action. 2017;10(1):1264702.

39. Sen T, Joshi SR, Udwadia ZF. Tuberculosis and diabetes mellitus: merging epidemics. J Assoc Physicians India. 2009;57(1):399-404.

40. Skowroński M, Zozulińska-Ziółkiewicz D, Barinow-Wojewódzki A. Tuberculosis and diabetes mellitus_-an underappreciated association. Arch Med Sci AMS. 2014;10(5):1019.

41. Bacakoğlu F, Başoğlu ÖK, Çok G, Sayıner A, Ateş M. Pulmonary tuberculosis in patients with diabetes mellitus. Respiration. 2001;68:595-600.

42. Chang J-T, Dou H-Y, Yen C-L, Wu Y-H, Huang R-M, Lin H-J, Su I-J, Shieh C-C. Effect of type 2 diabetes mellitus on the clinical severity and treatment outcome in patients with pulmonary tuberculosis: a potential role in the emergence of multidrug-resistance. J Formos Med Assoc. 2011;110(6):372-81

43. Gnanasan S: Pharmaceutical care for patients with tuberculosis and diabetes mellitus in Malaysia: a complex intervention. University of Nottingham; 2012

44. Jiménez-Corona ME, Cruz-Hervert LP, García-García L, Ferreyra-Reyes L, Delgado-Sánchez G, Bobadilla-del-Valle M, Canizales-Quintero S, FerreiraGuerrero E, Báez-Saldaña R, Téllez-Vázquez N. Association of diabetes and tuberculosis: impact on treatment and post-treatment outcomes. Thorax 2012. https://doi.org/10.1136/thoraxjnl-2012-201756.

45. Lin Y-H, Chen C-P, Chen P-Y, Huang J-C, Ho C, Weng H-H, Tsai Y-H, Peng Y-S. Screening for pulmonary tuberculosis in type 2 diabetes elderly: a cross-sectional study in a community hospital. BMC Public Health. 2015;15(1):3.

46. Amin S, Khattak MI, Shabbier G, Wazir MN. Frequency of pulmonary tuberculosis in patients with diabetes mellitus. Gomal J Med Sci. 2012;9(2):163-9.

47. Webb E, Hesseling A, Schaaf H, Gie R, Lombard C, Spitaels A, Delport S, Marais B, Donald K, Hindmarsh P. High prevalence of Mycobacterium tuberculosis infection and disease in children and adolescents with type 1 diabetes mellitus. Int J Tuberc Lung Dis. 2009;13(7):868-74.

48. Ji L-N, Lu J-M, Guo X-H, Yang W-Y, Weng J-P, Jia W-P, Zou D-J, Zhou Z-G, Yu D-M, Liu J. Glycemic control among patients in China with type 2 diabetes mellitus receiving oral drugs or injectables. BMC Public Health. 2013;13(1):602.

49. Kibirige D, Ssekitoleko R, Mutebi E, Worodria W. Overt diabetes mellitus among newly diagnosed Ugandan tuberculosis patients: a cross sectiona study. BMC Infect Dis. 2013;13(1):122.

50. Usmani RA, Nasir MI, Wazir S, Pervaiz Z, Zahra T, Akhtar M. Diabetes mellitus among tuberculosis patients in a tertiary care hospital of Lahore. J Ayub Med Coll Abbottabad. 2014;26(1):61-3.

51. Workneh MH, Bjune GA, Yimer SA. Prevalence and associated factors of tuberculosis and diabetes mellitus comorbidity: a systematic review. PLoS ONE. 2017;12(4):e0175925.

52. Dooley KE, Chaisson RE. Tuberculosis and diabetes mellitus: convergence of two epidemics. Lancet Infect Dis. 2009:9(12):737-46.

53. Jafta N, Jeena P, Barregard L, Naidoo R. Childhood tuberculosis and exposure to indoor air pollution: a systematic review and meta-analysis. Int J Tuberc Lung Dis. 2015;19(5):596-602.

54. Lönnroth K, Castro KG, Chakaya JM, Chauhan LS, Floyd K, Glaziou P, Raviglione MC. Tuberculosis control and elimination 2010-50: cure, care, and social development. Lancet. 2010;375(9728):1814-29.

55. World Health Organization. Collaborative framework for care and control of tuberculosis and diabetes. Geneva: World Health Organization; 2011. 
56. Thompson A, Bohling T, Heires A, Linder J, Rennard S. Lower respiratory tract iron burden is increased in association with cigarette smoking. J Lab Clin Med. 1991;117(6):493-9.

57. McGowan SE, Henley SA. Iron and ferritin contents and distribution in human alveolar macrophages. J Lab Clin Med. 1988;111(6):611-7.

58. Tripathy S, Kar K, Chakraborty D, Majumdar A. Diabetes mellitus and pulmonary tuberculosis. A prospective study. Ind J Tub. 1984;31(3):122-5.

59. Swai A, McLarty D, Mugusi F. Tuberculosis in diabetic patients in Tanzania. Trop Doct. 1990:20(4):147-50

60. Feleke Y, Abdulkadir J, Aderaye G. Prevalence and clinical features of tuberculosis in Ethiopian diabetic patients. East Afr Med J. 1999;76(7):361-4.

61. Qayyum ASM, Farogh A. Prevalence of pulmonary tuberculosis among diabetics. Biomedical. 2004;20:68-73.

62. Jabbar A, Hussain S, Khan A. Clinical characteristics of pulmonary tuberculosis in adult Pakistani patients with co-existing diabetes mellitus. East Mediterr Health J. 2006;12(5):522-7.

63. Kirui N, Pastakia S, Kamano J, Cheng S, Manuthu E, Chege P, Gardner A Mwangi A, Enarson D, Reid A. Important co-morbidity in patients with diabetes mellitus in three clinics in Western Kenya. Public Health Action. 2012;2(4):148-51.

64. Jali MV, Mahishale VK, Hiremath MB. Bidirectional screening of tuberculosis patients for diabetes mellitus and diabetes patients for tuberculosis. Diabetes Metab J. 2013;37(4):291-5.

65. Kumpatla S, Sekar A, Achanta S, Sharath B, Kumar A, Harries A, Viswanathan V. Characteristics of patients with diabetes screened for tuberculosis in a tertiary care hospital in South India. Public Health Action. 2013:3(1):23-8.

66. Prakash B, Ravish K, Prabhakar B, Ranganath T, Naik B, Satyanarayana $\mathrm{S}$, Isaakidis P, Kumar A. Tuberculosis-diabetes mellitus bidirectional screening at a tertiary care centre, South India. Public Health Action. 2013:3(1):18-22.

67. Rao MS, Shridhar M, Pavani K. VVE DS: screening of tuberculosis in diabetic patients at a tertiary care hospital in Hyderabad. Indian J Microbiol Res. 2015;2(4):220-6.
Ready to submit your research? Choose BMC and benefit from:

- fast, convenient online submission

- thorough peer review by experienced researchers in your field

- rapid publication on acceptance

- support for research data, including large and complex data types

- gold Open Access which fosters wider collaboration and increased citations

- maximum visibility for your research: over $100 \mathrm{M}$ website views per year

At BMC, research is always in progress.

Learn more biomedcentral.com/submissions 